\title{
Temperature and $\mathrm{GA}_{3}$ Effects on Emergence and Flowering of Potted Paeonia lactiflora
}

\author{
Michael R. Evans ${ }^{1}$, Neil O. Anderson ${ }^{1}$, and Harold F. Wilkins ${ }^{2}$ \\ Department of Horticultural Science and Landscape Architecture, \\ University of Minnesota, St. Paul, MN 55108
}

Additional index words. peony, dormancy

\begin{abstract}
Various durations of rooting at $15 \mathrm{C}$ and storage at 5.X and exogenous GA, $(1000 \mathrm{ppm})$ application were used on dormant unrooted peony (Paeonia lactiflora Pall.) tubers of 'Sarah Bernhardt', 'Festiva Supreme' 'Krinkled White', and 'Scarlet O'Hara'. Four weeks of cooling were sufficient to break dormancy. Days to emergence, first bud color, and anthesis were reduced as the length of cold storage increased from 4 to 20 weeks. Height and number of shoots emerging per pot increased with increased cooling. All flower buds aborted when tubers were cooled for 20 weeks. When noncooled tubers were given a 1000-ppm GA, soil drench, shoots emerged within 7.5 days; untreated tubers failed to emerge after 5 months. When tubers were treated with GA, all flower b u d s a b o r t ed.
\end{abstract}

Herbaceous peonies are common perennials that have been used as garden plants for over 2000 years (Liberty Hyde Bailey Hortorium, 1976) and have been grown commercially as cut flowers for many years. The cultivar Sarah Bernhardt has been advertised as a cut flower in Holland for domestic and export spring sales in recent years (Holland Flower, 1981-1987). In the continental United States, peonies have been grown throughout much of the country as cut flowers (Evans and Anderson, 1987.)

Historically, peonies have been forced under greenhouse conditions to hasten flowering (Nehrling and Nehrling, 1960; Wilkins and Halevy, 1985). Clumps of rooted tubers were dug and potted in early fall (September through October), placed in cold frames for a cold treatment, and brought into the greenhouse for forcing in late December. Optimal forcing temperatures have been reported to be 13 to 16C (Wilkins and Halevy, 1985). Higher temperatures may cause flower bud abortion (Byrne and Halevy, 1986).

Byrne and Halevy (1986) indicated that flower bud initiation occurred after the current year's flower reached anthesis in June. Flower bud development continued until the onset of dormancy in the fall. Flower bud dormancy of rooted clumps could be broken by a minimum of 4 weeks of holding at 5.6C. Plants then flowered in 8 to 10 weeks when forced in the greenhouse. However, it has

\footnotetext{
Received for publication 17 July 1989 . Scientific Journal Series Paper no. 17,194 of the Minnesota Agriculture Experiment Station. We thank Klehm Nursery of Champaign, Ill., for their support of this project. The cost of publishing this paper was defrayed in part by the payment of page charges. Under postal regulations, this paper therefore must be hereby marked advertisement solely to indicate this fact.

${ }^{1}$ Graduate Assistant.

2Professor. Current Address: 2651 Cabrillo Highway N., Half Moon Bay, CA 94019.
}

not been determined whether unrooted peony tubers may be potted, rooted, and given a dormancy-breaking treatment under controlled conditions. The objective of the current study was to determine if unrooted tubers could be rooted, given a dormancy-breaking 'treatment, and rapidly forced in the greenhouse as potted plants.

For all experiments, unrooted tubers (three to five buds) were shipped from Champaign, Ill., to St. Paul, Minn., immediately after harvest in October. They then were potted in $305-\mathrm{cm}^{3}$ pots containing an artificial medium consisting of 3 peat : 1 perlite : 1 loam (by volume). Within cultivars, tubers were randomly assigned to treatments. Rooting, cold storage, and greenhouse forcing were at $16,5.5$, and $18 \mathrm{C}$, respectively. Plants were fertilized with $200 \mathrm{ppm} \mathrm{N}$ using various proportions of $\mathrm{Ca}\left(\mathrm{NO}\right.$ ą) $\mathrm{KNO}_{3}$. Micronutrients and fungicides were applied monthly.

In the first experiment, 'Sarah Bernhardt', 'Festiva Supreme', and 'Krinkled White' were subjected to either 0,2 , or 4 weeks of rooting and then to 4 or 6 weeks of cooling before forcing in the greenhouse. The number of days to emergence, to first bud color, and to anthesis, and the height and number of shoots emerging per pot were recorded. Ten pots were used per treatment. An analysis of variance was performed to test treatment and cultivar differences. Separation of means was performed by Fisher's least significant difference test.

In the second experiment, 'Scarlet O'Hara' was used to test the effect of extended cooling periods on subsequent shoot growth and flowering. All tubers were given 4 weeks of rooting before being held in cold storage 6 , $8,10,14$, or 20 weeks. Thereafter, plants were forced in the greenhouse. Ten pots were used per treatment. The same characteristics were recorded as for the first experiment. Each characteristic was regressed against time. The treatment means, line equations, and $r^{2}$ values were determined.
In the third experiment 'Scarlet O'Hara' was used to determine if gibberellic acid $\left(\mathrm{GA}_{3}\right)$ could be used to break dormancy of noncooled tubers. Tubers were placed in the greenhouse for forcing immediately after potting and received either 0 or $1000 \mathrm{ppm}$ (118 mg a.i./pot) $\mathrm{GA}_{3}$ as a soil drench. The number of shoots that emerged and days to emergence were recorded. Six pots were used per treatment.

In expt. 1, the number of days to shoot emergence was reduced with increased rooting time (Table 1). In expts. 1 and 2, the number of days to emergence was reduced with longer cold storage (Tables 1 and 2). 'Krinkled White' emerged sooner than 'Sarah Bemhardt' and 'Festiva Supreme' (Table 1). For 'Scarlet O'Hara', tubers held for 20 weeks emerged while at $5.5 \mathrm{C}$, i.e., before greenhouse forcing (Table 2).

Terminal flower bud abortion limited the number of observations for days to first bud color and anthesis. Bud abortion was most prevalent on 'Sarah Bernhardt' and 'Festiva Supreme' in expt. 1. In expt. 2, all 'Scarlet O'Hara' tubers stored cold for 20 weeks had terminal flower buds abort. Results for days to first bud color and anthesis were based on those buds reaching the respective developmental stages. The number of days to first bud color was unaffected by the length of the rooting and cooling treatments in expt. 1 (Table 1 ). When not preceded by a rooting treatment, the number of days to anthesis was reduced as the length of cold storage increased. When preceded by a rooting treatment, the duration of cold storage did not significantly affect the number of days to anthesis. 'Krinkled White' required fewer days to reach first bud color than either 'Sarah Bernhardt' or 'Festiva Supreme'. In expt. 2, the number of days to first bud color and anthesis was reduced with increased cold storage (Table 2).

In expt. 1, height increased as the length of cold storage was increased from 4 to 6 weeks (Table 1). However, for 'Scarlet O'Hara' in expt. 2, height was not correlated with increased cooling time (Table 2). Heights for all cultivars ranged from $\approx 22$ to $36 \mathrm{~cm}$.

The number of shoots emerging per pot was not significantly affected by either duration of the rooting or cold storage in expt. 1. 'Krinkled White' produced more shoots than 'Sarah Bernhardt', which produced more shoots than 'Festiva Supreme'. For 'Scarlet O'Hara' in expt. 2, the mean number of shoots per pot increased with increased storage time (Table 2); however, the number of shoots was not highly correlated with this variable $\left(r^{2}=0.26\right)$.

Tubers treated with $\mathrm{GA}_{3}$ emerged $7.5 \pm$ $1.5(\times \pm \mathrm{SD})$ days following the application. GA,-treated tubers initially produced $4.1 \pm$ 1.7 shoots per pot and were $31.7 \pm 4.1 \mathrm{~cm}$ high 4 weeks after the treatment. Control plants failed to emerge after 5 months, even though they were well-rooted.

All flower buds aborted on $\mathrm{GA}_{3}$-treated tubers. It is plausible that the abortion was induced by the high rate of $\mathrm{GA}_{3}$ and that lower rates might overcome dormancy with- 
Table 1. Effects of rooting (16C) and cooling (5.5C) treatments on emergence and flowering of Paeonia lactiflora 'Sarah Bernhardt', 'Festiva Supreme', and 'Krinkled White' tubers (expt. 1).

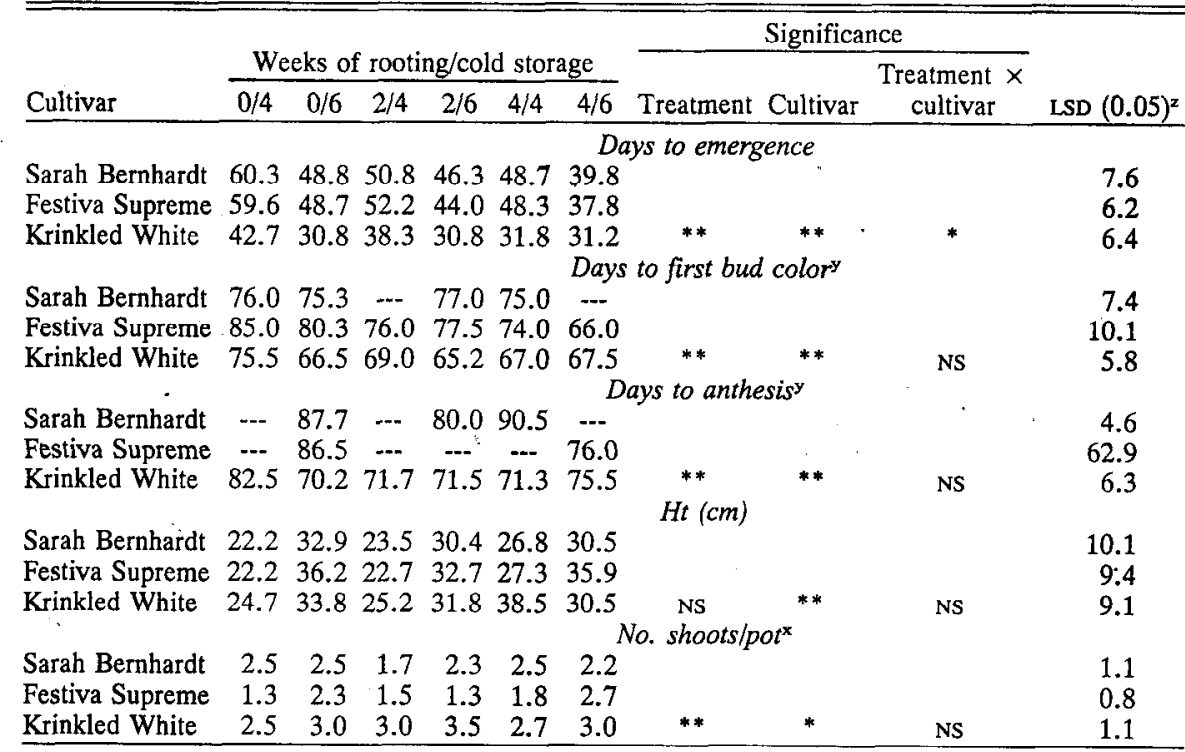

${ }^{2}$ Mean separation within rows, Fisher's least significant difference test, $5 \%$ level. Each treatment consisted of 10 pots with a pot constituting a replication.

y some cases terminal flower buds aborted prior to showing color and reaching anthesis.

${ }^{x}$ Combination of vegetative and reproductive shoots.

Ns,*,**Nonsignificant or significant at $P=0.05$ or 0.01 , respectively.

Table 2. Effect of 4 weeks of rooting (16C) and duration of cold storage (5.5C) on emergence and flowering of Paeonia lactiflora 'Scarlet O'Hara' tubers (expt. 2).

\begin{tabular}{|c|c|c|c|c|c|c|c|}
\hline \multirow[b]{2}{*}{ Criterion } & \multicolumn{5}{|c|}{ No. weeks of cold storage } & \multirow[b]{2}{*}{ Line equation } & \multirow[b]{2}{*}{$r^{2}$} \\
\hline & 6 & 8 & 10 & 14 & 20 & & \\
\hline Days to emergence & 37.0 & 27.4 & 23.5 & 18.9 & $0.0^{\mathbf{z}}$ & $y=41.4-5 x$ & 0.85 \\
\hline Days to bud color & 67.5 & 54.5 & 47.5 & 26.7 & $\ldots y$ & $y=76.9-10 x$ & 0.89 \\
\hline Days to anthesis & 72.4 & 58.7 & 51.9 & 29.4 & --- & $y=83.1-9 x$ & 0.82 \\
\hline $\mathrm{Ht}(\mathrm{cm})$ & 26.7 & 22.7 & 32.6 & 27.8 & 33.1 & $y=23.3-2 x$ & 0.09 \\
\hline No. shoots/potx & 2.0 & 2.7 & 3.0 & 2.9 & 3.2 & $y=1.1+0.8 x$ & 0.26 \\
\hline
\end{tabular}

2Tubers emerged in cooler before greenhouse forcing.

YTerminal flower buds aborted before showing color and reaching anthesis.

${ }^{x}$ Combination of vegetative and reproductive shoots.

out causing bud abortion. Additional vegetative shoots continued to emerge up to 12 weeks after the $\mathrm{GA}_{3}$ treatment. These shoots appeared to arise from buds initiated after harvest. It is unclear whether these would have normally developed as reproductive shoots during the next season had $\mathrm{GA}_{3}$ not been applied.

Azaleas are the only other floricultural crop where GA, has been demonstrated to completely substitute for a dormancy-breaking cold requirement (Ballantyne and Link, 1961; Boodley and Mastalerz, 1959), although in some species, gibberellins have been shown to partially substitute for a cold treatment (Moe and Berland, 1986; Rees and Hanks, temperatures have been reported to cause flower bud abortion in peony. Further, photoperiod might be involved, as all treatments were forced under photoperiods significantly shorter than the photoperiod under which peonies normally emerge and flower.

Based on these studies, it would be possible to root, provide a dormancy-breaking cold treatment, and force herbaceous peonies under controlled conditions using unrooted tubers rather than large clumps. If more flowers per tuber could be obtained by reducing flower bud abortion, the herbaceous peony could be adapted to pot culture. Commercially available cultivars. have diverse flower types and canopy forms. Therefore, cultivar selection would be necessary to determine those cultivars best suited for this type of culture.

\section{Literature Cited}

Ballantyne, D.J. and C.B. Link. 1961. Growth regulators and the flowering of evergreen azaleas, Rhododendron cv. Proc. Amer. Soc. Hort. Sci. 78:521-531.

Boodley, J.W. and J.W. Mastalerz. 1959. The use of gibberellic acid to force azaleas without a cold temperature treatment. Proc. Amer. Soc. Hort. Sci. 74:681-685.

Byrne, T.G. and A.H. Halevy. 1986. Forcing herbaceous peonies. J. Amer. Soc. Hort. Sci. 111(3):379-383.

Evans, M.R. and N.O. Anderson. 1987. The history and culture of the herbaceous peony. Minn. State Flor. Bul. 36(4):8-10.

Holland Flower. 1981-1987. Summer flowers from Holland. North American ed. Bloemenbureau Holland, Leiden, Netherlands.

Liberty Hyde Bailey Hortorium. 1976. Hortus third: A concise dictionary of plants cultivated in the United States and Canada. 3rd ed. Macmillan, New York.

Moe, R. and M. Berland. 1986. Effect of various corm treatments on flowering of Liatris spicata Willd. Acta Hort. 177: 197-201.

Nehrling, A. and I. Nehrling. 1960. Peonies, outdoors and in. Heartside, New York.

Rees, A.R. and G.R. Hanks. 1979. Potential uses of plant growth regulators in bulb growing and forcing. Acta Hort. 91:153-159.

Rudnicki, R.M., J. Nowak, and M. Saniewski. 1976. The effect of gibberellic acid on sprouting and flowering of some tulip cultivars. Scientia Hort. 4:387-397.

Saniewski, M., J. Nowak, and R.M. Rudnicki. 1977. The physiology of hyacinth bulbs. Xl. The effect of gibberellic acid on the growth and flowering of variously chilled bulbs. Scientia Hort. 7:179-184.

Wilkins, H.F. and A.H. Halevy. 1985. Paeonia, p. 2-4. In: A.H. Halevy (ed.). CRC Handbook of flowering IV. CRC, Boca Raton, Fla. 